\title{
Retruded Cuspal Position and Terminal Hinge Axis
}

\author{
Bulent Piskin, DDS, $\mathrm{PhD}^{1}$; Alper Uyar, DDS, $\mathrm{PhD}^{2}$ \\ ${ }^{1}$ Cappadocia University, Faculty of Dentistry, Department of Prosthodontics, Urgup, Turkey; ${ }^{2}$ Health Science University, Gulhane Dental \\ School, Department of Prosthodontics, Istanbul, Turkey
}

The diagram formed by the range of border movements of the mandible in the sagittal plane was first defined by Posselt and known as Posselt's Envelope of Motion. ${ }^{1}$ In the well-planned study of $\mathrm{Ng}$ et $\mathrm{al}^{2}$ in which the authors compared the efficiencies of the sibilant phoneme and anterior protrusive techniques for the determination of the amount of mandibular protrusion of mandibular advancement devices, the most superior and posterior position on the envelope of motion (Figure 3 in $\mathrm{Ng}$ et al's article) was referred to as retruded cuspal position (RCP). However, the accurate term for this point of the envelope should be centric relation (CR). ${ }^{1-3}$

Undoubtedly, the most reliable source for understanding whether this point of the envelope is RCP or CR is the Glossary of Prosthodontic Terms (GPT). In the latest edition of the GPT ${ }^{1}, \mathrm{CR}$ has been defined precisely as "a maxillomandibular relationship, independent of tooth contact, in which the condyles articulate in the anteriorsuperior position against the posterior slopes of the articular eminences". ${ }^{1}$ As the definition suggests, CR is completely independent of any tooth contact and is a boneto-bone relationship. ${ }^{1,5}$ According to this definition, it seems impossible to define this point of envelope as RCP in Figure 3 in $\mathrm{Ng}$ et al's article ${ }^{2}$. The point marked RCP in Figure 3 is indicated as $\mathrm{CR}$ in one of the most reliable textbooks published on this subject. ${ }^{5}$

Tooth contacts can also occur when the jaws are in CR. ${ }^{1,5}$ Tooth contacts that occur between the mesial inclination of the maxillary posterior teeth and the distal inclination of the mandibular posterior teeth are called as premature contacts. ${ }^{1,5}$ The most important reason why the term RCP is still used in some reference books is that the term and its meaning is perhaps one of the most controversial issues in the history of dentistry.

Another remarkable flaw of Figure 3 is the name of the point at the end of the 20- to 25-mm-long mandibular opening movement by pure rotation of the condyles' terminal hinge axis (THA). THA is the imaginary horizontal axis connecting the condyles around which the mandible performs pure rotation. ${ }^{1,5}$ Thus, it is much more accurate to use the term posterior opening boundary movement rather than the term THA. ${ }^{5}$

\section{CITATION}

Piskin B, Uyar A. Retruded cuspal position and terminal hinge axis. J Dent Sleep Med. 2021;8(4).

\section{REFERENCES}

1. Ferro KJ, Morgano SM, Driscoll CF, et al. Glossary of Prosthodontic Terms. Ninth Edition. J Prosthet Dent. 2017;117:e1-e105.

2. $\quad \mathrm{Ng}$ ET, Mayoral P, Hernandez IA, Manuel O. Lagravère MO. Comparing anterior protrusive with sibilant phoneme mandibular positioning techniques for dental sleep appliances in managing obstructive sleep apnea: A retrospective study. J Dent Sleep Med. $2021 ; 8(1)$.

3. Wilson PHR, Banerjee A. Recording the retruded contact position: a review of clinical techniques. Br Dent J. 2004;196:395-402.

4. Koolstra JH, Naeije M, van Eijden TM. The three-dimensional active envelope of jaw border movement and its determinants. J Dent Res. 2001;80:1908-1912.

5. Okeson JP. Mechanics of mandibular movements, in Management of Temporomandibular Disorders and Occlusion. St Louis, MO, Mosby, 2013, pp 63-73.

\section{SUBMISSION AND CORRESPONDENCE INFORMATION}

Submitted for publication April 22, 2021

Submitted in final revised form June 22, 2021

Accepted for publication June 27, 2021

Address correspondence to: Bulent Piskin, DDS, PhD, Hadosan kampüsü Cappadocia University, Faculty of Dentistry, Urgup, Turkey; Phone: +90 50624244 44; Email: piskin_bulent@yahoo.com

\section{DISCLOSURE STATEMENT}

The authors have no relevant conflicts of interest to disclose. 